\title{
MULTICULTURALISMO NEOLIBERAL Y TRANSNACIONALIZACIÓN DE LOS PUEBLOS INDÍGENAS EN LA FRONTERA MÉXICO-Estados Unidos
}

\author{
NeOliberal Multiculturalism and Transnationalization \\ of Indigenous Peoples in the Mexico-U.S. Border
}

\author{
Mao Fukuma* \\ doi: https://doi.org/10.31644/ED.V9.N1.2022.A06
}

\begin{abstract}
Resumen: A partir de los años noventa, los pueblos indígenas en la frontera México-Estados Unidos, los yaquis y los kumiai/Kumeyaay, empezaron a organizarse para reforzar lazos étnicos perdidos durante mucho tiempo. Para entender este acercamiento más allá de la frontera, se requiere revisar una serie de políticas neoliberales y multiculturales, así como los movimientos indígenas ocurridos en ambos países. La confluencia de ambos procesos trae consecuencias diferentes según el lado de la frontera en el que se encuentran: en uno, el aparente empoderamiento en la arena política y económica gracias al emprendimiento de negocios tribales y el afán de recuperar patrimonio cultural tangible e intangible; y en el otro lado, el empobrecimiento, la desigualdad y el despojo constante de territorio y recursos naturales. Estos cambios que ocurrieron durante las décadas anteriores han creado la base para la transnacionalización de estos pueblos indígenas en la frontera, creando resistencias y alianzas transnacionales. Sin embargo, al mismo tiempo, estos enfrentan un mayor obstáculo, la frontera México-Estados Unidos.
\end{abstract}

Palabras clave: gubernamentalidad, transnacionalismo, frontera internacional, yaqui, kumiai/Kumeyaay.

Abstract: Beginning in the 1990s, Mexican and American transborder indigenous peoples, the Yaquis and the kumiai/Kumeyaay, began to organize to strengthen long-lost ethnic ties. To understand this transborder approach it is necessary to review a series of the neoliberal and multicultural policies, as well as the indigenous movements that have occurred in both countries. The confluence of both processes generates different outcomes for indigenous groups depending on the side on which they find themselves: on the one hand, the apparent empowerment in the

\footnotetext{
* Dra. en Ciencias Antropológicas, profesora investigadora Universidad de Kansaigaidai, Japón. Correo-e: maomao0105i@hotmail.co.jp.

Fecha de recepción: 30/05/2021. Fecha de aceptación: 18/11/2021. Fecha de publicación: 31/01/2022.

(cc) BY-NC-ND
}

EntreDiversidades. Revista de Ciencias Sociales y Humanidades, Vol. 9, Núm. 1 (18), enero-junio 2022. Páginas: 148-175 ISSN-e: 2007-7610. https://doi.org/10.31644/ED.V9.N1.2022.A06 
political and economic arena thanks to tribal business ventures and the interest in recovering tangible and intangible cultural heritage; and on the other hand, the impoverishment, inequality and constant dispossession of territory and natural resources. These changes occurred during the previous decades have created base for the transnationalization of these transborder indigenous peoples, thus creating transnational resistances and alliances, but at the same time, they face a major obstacle, the U.S.-Mexico border.

Keywords: governmentality, transnationalism, international border, Yaquis, kumiai/Kumeyaay.

\section{Introducción}

Los estudios transnacionales se desarrollaron a medida que los procesos globales y transnacionales avanzaban velozmente. Los trabajos pioneros del transnacionalismo señalan la existencia de migrantes cuya vida trasciende las fronteras nacionales incorporando las instituciones, las actividades y las rutinas diarias que se sitúan tanto en el país de destino como transnacionalmente (Glick Schiller, Basch y Blanc-Szanton, 1992; Levitt y Glick Schiller, 2004), o también indican la presencia de comunidades transnacionales formadas por movimientos de personas entre localidades internacionales, generados por imperativos de los mercados laborales y sus propias condiciones de vida económica (Kearney y Nagengast, 1989: 1). Este nuevo enfoque que se desprende de los viejos estudios de la migración comprende la transnacionalidad como un proceso de construcción del Estado-nación, cuestionando el concepto de "nación" como constructo acabado (Glick Schiller, Basch y Blanc-Szanton, 1992; Besserer, 1999). A pesar de estos avances, durante muchos años la mayoría de estos estudios, así como los trabajos etnológicos, ${ }^{1}$ pasaron por alto a los pueblos indígenas divididos por la frontera - ya que la frontera les cruzó- - y sus prácticas transnacionales. Esta tendencia "nacioncentrista" ya no se puede sostener, pues cada vez más sus prácticas transnacionales y transfronterizas se encuentran más visibilizadas, lo que nos obliga a buscar y explorar otros enfoques analíticos para explicar la dinámica social y cultural que sucede más allá de un Estado-nación. Aunque cada uno de estos dos pueblos indígenas difiere en su extensión territorial en la región transfronteriza y en sus relaciones con los Estados — sus derechos culturales, políticos y económicos- debido a los diferentes procesos de incorporación en los dos países, existen similitudes y correspondencias entre ellos.

\footnotetext{
${ }^{1}$ Por ejemplo, uno de los antropólogos más famosos de los estudios etnológicos en la región suroeste de Estados Unidos, Edward Spicer, nunca hizo un estudio de los yaquis con perspectiva transnacional. De la misma manera, hasta hace dos décadas los pueblos indígenas en la frontera no fueron estudiados en conjunto y todos los trabajos antropológicos y etnológicos se detenían en la frontera internacional. En la actualidad, ya contamos con algunos trabajos con perspectiva transnacional que abordan con enfoque histórico o etnográfico, por ejemplo, Von Barsewisch (2006), Mager (2010), Leza (2009), Schulze (2008), Guidotti-Hernández (2011), Hays (1996), entre otros.
}

EntreDiversidades. Revista de Ciencias Sociales y Humanidades, Vol. 9, Núm. 1 (18), enero-junio 2022. Páginas: 148-175 ISSN-e: 2007-7610. https://doi.org/10.31644/ED.V9.N1.2022.A06 
Ante la creciente presencia en el espacio transfronterizo de los pueblos indígenas en la frontera $^{2}$ es pertinente hacer una pregunta: ¿En qué contexto se desarrolló y se visualizó la transnacionalización de estos pueblos? Mi hipótesis es que el cambio de las políticas indígenas tanto en Estados Unidos como en México dio una base para el acercamiento más allá de la frontera. En otras palabras, para entender el fenómeno emergente y las prácticas actuales es importante analizar procesos políticos en el nivel translocal y transnacional. No obstante, decirlo de esta manera no implica que no existieran anteriormente vínculos sociales y culturales más allá de la frontera, porque estos pueblos ya se habían transnacionalizado a partir del establecimiento de la frontera en 1853. Por tanto, más bien lo que me interesa indagar es cómo las coyunturas políticas particulares crearon una escena en la que estos pueblos reforzaran sus conexiones sociales e imaginaran "una" nación más allá de la frontera, ya que esto no fue un accidente, sino el resultado de una serie de políticas y de la emergencia indígena en la escala global, lo que posibilitó el surgimiento de identidades políticas y culturales que rebasan la frontera internacional y crean prácticas transnacionales que desafían el poder.

Para comprender la forma actual de transnacionalidad, así como resistencias y retos de los pueblos indígenas en la frontera México-Estados Unidos, primero analizaré las políticas del "multiculturalismo neoliberal" (Hale, 2005b) y los movimientos indígenas en ambos países; después, examinaré la correlación entre dichas políticas y el endurecimiento de la frontera estatal y la construcción de las fronteras tanto políticas como culturales. ${ }^{3}$ Finalmente, señalaré dos casos concretos, los yaquis y los kumiai/Kumeyaay.

\section{Multiculturalismo neoliberal y movimientos indígenas en México y Estados Unidos}

Entre la década de los sesenta y noventa hubo intensas transformaciones en muchos sentidos. Los procesos globales y transnacionales cuestionaron la capacidad de los Estados-naciones para administrar, establecer y efectuar normas, reglamentos y políticas dentro de sus territorios (Hanson, 2004), y, al mismo tiempo, los grupos subalternos y marginados empezaron a levantar la voz de protesta y revindicar sus derechos en distintos lugares del mundo. La articulación a diferentes escalas con los actores y las instituciones en la arena política para solucionar problemas locales y nacionales (a mencionar algunos, la Organización de la Naciones Unidas, las organizaciones no gubernamentales, las universidades, las asociaciones civiles, etc.) les abrió la posibilidad de tomar estrategias variables, así como les permitió extender la alianza pan-indígena a nivel nacional, transnacional y global.

\footnotetext{
${ }^{2}$ Defino los pueblos indígenas en la frontera México-Estados Unidos como pueblos que mantenían la movilidad en la actual zona fronteriza antes del establecimiento de la frontera en 1853 y que residen actualmente en dicha zona y son políticamente reconocidos como indígenas o Native American por cada gobierno. Bajo esta definición, los pueblos como los yaquis y los kikapú, cuyos territorios "originales" no se sitúan en la actual zona transfronteriza, también pertenecen a esta categoría.

${ }^{3}$ En este trabajo no abordo las fronteras culturales. Para el caso de los yaquis, véase Fukuma (2018).
}

EntreDiversidades. Revista de Ciencias Sociales y Humanidades, Vol. 9, Núm. 1 (18), enero-junio 2022. Páginas: 148-175 ISSN-e: 2007-7610. https://doi.org/10.31644/ED.V9.N1.2022.A06 
En los procesos reivindicativos la llegada del neoliberalismo marcó un cambio no solo en el campo económico, sino también en las políticas indígenas en ambos países. Las políticas neoliberales son entendidas en general como favorecedoras de la reducción del poder del Estado en términos políticos y económicos, ya que "la mejor forma de promover el bienestar del ser humano consiste en no restringir el libre desarrollo de las capacidades y de las libertades empresariales del individuo dentro de un marco institucional caracterizado por derechos de propiedad privada fuertes, mercados libres y libertad de comercio" (Harvey, 2007: 6). De esta forma, el Estado delega poder al individuo como responsable de sí mismo, autodirigido, autorregulado, ciudadano aparentemente empoderado (Besserer y Nieto, 2015), considerando a la colectividad como una comunidad autosustentada y autodirigida, acorde al capitalismo global. En este sentido, basándose en la noción de gubernamentalidad de Foucault, Aihwa Ong afirma que "el neoliberalismo como una tecnología de gobierno, la gubernamentalidad es resultado de la infiltración de verdades y cálculos derivados del mercado en el dominio político" (2006: 4).

Aunque este cambio puede interpretarse como empoderamiento de los actores indígenas o democratización del sistema político, el marco de la gubernamentalidad sugiere que el mantenimiento del orden político solo se institucionaliza de forma más eficiente e insidiosa a medida que se dispersa mediante la "transferencia" (Biolsi, 2004: 243). En efecto, estas políticas les han traído una serie de consecuencias, pero de forma diferente; por un lado, los indígenas mexicanos se encuentran cada vez más desposeídos y vulnerables a los (mega) proyectos nacionales y transnacionales bajo pretensiones de ampliar los marcos de desarrollo económico, y por el otro, los indígenas estadounidenses, Native American, se muestran aparentemente más "empoderados" en el contexto nacional mediante el acceso al mercado turístico.

En Estados Unidos las políticas neoliberales iniciaron con la administración del presidente Reagan, quien emprendió las reformas estructurales mediante el recorte en el gasto social y educativo. Este recorte impactó considerablemente a los Native American que dependían de los programas sociales que ofrecía el gobierno federal (Hanson, 2004). No obstante, las políticas neoliberales de Reagan respondieron, al fin y al cabo, a su reclamación histórica, la autonomía económica. Bajo su administración, los Native American salieron de la dependencia del gobierno federal y emprendieron el negocio tribal en la reservación, convirtiéndose, en cierto sentido, en empresa étnica o "etnoempresa" (Comaroff y Comaroff, 2009). Las actividades de juegos de azar y otros negocios tribales les posibilitaron tener estabilidad económica, y, de esta manera, ejercer su influencia en la arena política estatal y nacional, e incluso, en algunos casos, desafiar al poder del Estado.

En cambio, en México las políticas neoliberales iniciaron a partir de la administración de Miguel de la Madrid tras la crisis económica del 1982, y se aceleraron durante el gobierno de Salinas de Gortari: las reformas agrarias, la canalización del Tratado de Libre Comercio (TLC) o la implementación de proyectos de asistencia social transformaron considerablemente la vida de muchos pueblos indígenas. Sobre todo, la Reforma Agraria (1992), que permitió la privatización, venta, hipoteca y arrendamiento de tierras ejidatarias, junto con la eliminación de subsidios y soportes de precio, así como la reducción de créditos a pequeños productores, lo que minó la vida rural y dificultó a los pequeños productores indígenas mantenerse en la agricultura.

EntreDiversidades. Revista de Ciencias Sociales y Humanidades, Vol. 9, Núm. 1 (18), enero-junio 2022. Páginas: 148-175 ISSN-e: 2007-7610. https://doi.org/10.31644/ED.V9.N1.2022.A06 
Y, posteriormente, el TLC, con el aumento de la competitividad de los productos agrícolas extranjeros que provocó el abandono de la agricultura como medio de subsistencia, y, con ello, la aceleración de la migración en busca de trabajo y la venta y/o renta de las tierras ejidatarias (Weaver, et al., 2012). Por otro lado, varias reformas sociales durante la administración de Salinas, como el Programa Nacional de Solidaridad (PRONASOL), buscaron reconocer (ciertos) derechos a los pueblos indígenas para facilitar su integración al mercado como ciudadanos y reducir la responsabilidad social y el papel tradicional de tutelaje del Estado, lo que Saldívar llama "indigenismo legal” (2003: 314). En términos económicos, los gobiernos y las instituciones gubernamentales empiezan a apoyar y ofrecer créditos a ciertos proyectos que les permitan autogestionarse y autodirigirse, pero no como una comunidad sino como "ciudadano" o "empresa”, de esta manera, se espera crear ciudadanos-consumidores responsables de sus propios actos y riesgos asociados.

Por otro lado, las décadas de los ochenta y los noventa son épocas de "presénce indigène" (Clifford, 2013) a escala global, tras la emergencia indígena notable en la arena política nacional e internacional. En Estados Unidos, la resistencia indígena a partir del Red Power Movement dio frutos significativos para conseguir la autodeterminación política y cultural. Como consecuencia, durante las últimas décadas del siglo XX se promulgaron leyes importantes, por ejemplo, Indian Self-Determination and Education Assistance Act of 1975 (Ley de Autodeterminación y Asistencia Educativa de los Indígenas de 1975), American Indian Religious Freedom Act (1978) (Ley de Libertad Religiosa de los Indígenas Norteamericanos, 1978), Native American Graves Protection and Repatriation Act (1990) (Ley de Protección de Tumbas de Nativos Americanos y Repatriación, 1990), etc. Gracias a estas movilizaciones y resistencias, según Biolsi (2005), los Native American han ganado cuatro espacios políticos en Estados Unidos: 1) el espacio tribal, la reservación donde los gobiernos tribales ejercen su poder soberano; 2) el espacio de coadministración de recursos naturales (ríos, montañas, etc.) con los gobiernos municipales o estatales; 3) el espacio nacional donde los indígenas ejercen sus derechos portátiles ${ }^{4}$ más allá de las reservaciones; y 4) el espacio político donde dos naciones, el Estado-nación y la nación tribal coexisten en el espacio físico. Aquí, desde mi perspectiva, se tiene que agregar el "espacio transnacional", donde los pueblos indígenas transfronterizos exigen derechos indígenas al (libre) cruce fronterizo de los miembros e intervienen en asuntos políticos y económicos que enfrentan las comunidades emparentadas en el otro lado de la frontera (Fukuma, 2018). En este caso, el poder de negociar con los gobiernos y las instituciones gubernamentales tanto de Estados Unidos como de México emana de su estatus particular como Native American, y ese poder se extiende al espacio transnacional, puesto que la diferencia nace de su condición preconstitucional, su existencia antes de la formación del Estadonación, por su "prioridad" temporal (Biolsi, 2005).

En cambio, en México, como respuesta a las reformas neoliberales, a partir de los noventa los indígenas empezaron a movilizarse y exigir sus reivindicaciones históricas — la educación bilingüe, el derecho a la autonomía y a las tierras y los recursos, entre otros-, como en el caso del levantamiento zapatista, que se visualizó y se difundió a escala mundial. Estas resistencias,

\footnotetext{
${ }^{4}$ Los derechos portátiles son los que los indígenas pueden ejercer fuera de la reservación, tales como el de la compra, posesión y consumo de peyote como motivo religioso.
}

EntreDiversidades. Revista de Ciencias Sociales y Humanidades, Vol. 9, Núm. 1 (18), enero-junio 2022. Páginas: 148-175 ISSN-e: 2007-7610. https://doi.org/10.31644/ED.V9.N1.2022.A06 
junto con presiones de las organizaciones internacionales como la Organización de las Naciones Unidas, obligaron al gobierno federal a atender constitucionalmente los derechos indígenas y proclamar la Ley Indígena (2001), aunque esta fue rechazada por el conjunto de organizaciones indígenas. Si bien el reconocimiento pleno de derechos colectivos sigue sin ser autorizado, ha habido avances democráticos en ciertas estructuras del Estado, tales como el Congreso de la Unión o la Suprema Corte de Justicia de la Nación (SCJN), y en la toma de decisiones del poder, abriendo así espacios para los integrantes indígenas en la estructura política (Valladares, 2008). Sobre todo, han aumentado considerablemente los intentos de recurrir a la SCJN a partir de la implementación de políticas del multiculturalismo neoliberal (Valladares, 2008).

Es claro que el giro político tanto en México como en Estados Unidos ha creado las condiciones para la reivindicación de los derechos indígenas, desde los derechos políticos y culturales hasta las exigencias territoriales y el control de recursos naturales. Sin embargo, la combinación de las políticas neoliberales (libre comercio, reducción del Estado, emprendimiento individual, etc.) y las políticas de diferencia, el multiculturalismo (el reconocimiento de "ciertos" derechos culturales, la eliminación de la desigualdad, etc.), como argumenta Charles Hale, trae consecuencias serias: estas reformas tienden a empoderar a algunos y marginar a la mayoría a través de la manipulación de dos categorías, basadas ya no en las diferencias raciales (mestizo e indígena), sino en las culturales y políticas, "indio permitido" e "indio radical” (2016). De acuerdo con Hale, mientras el gobierno reconoce ciertos derechos culturales, las políticas del multiculturalismo neoliberal generan límites que abortan las aspiraciones más transformadoras o más "radicales" a través de "la transmisión de mensaje implícito de que está bien que los indígenas gocen de ciertos derechos siempre y cuando dejen de exigir los demás" (Hale, 2005a: 5). Las consecuencias de estas políticas, al fin y al cabo, son las que el Estado adquiere como una nueva forma de neutralizar los movimientos indígenas y gobernar a los ciudadanos de manera más eficaz (2005a). ${ }^{5}$

En México, si bien las políticas neoliberales provocaron aún más el despojo de las tierras y de los recursos naturales y empujaron masivamente a la población rural marginada a migrar a los centros, o bien a Estados Unidos, el multiculturalismo neoliberal también conlleva un proyecto que responde a las voces indígenas. En el caso mexicano, el reconocimiento cultural no trae consigo los derechos colectivos a tierras y recursos, ni a la autonomía; pero el proyecto cultural neoliberal abre un espacio para reivindicar la identidad cultural y entrar en el mercado de identidad, ya que estas políticas permiten, e incluso fomentan, amplias latitudes de libertad para ser culturalmente diferentes, aunque dentro de los límites impuestos por el proyecto nacional y la protección de la acumulación capitalista (Clifford, 2013: 17; Hale, 2016). Específicamente, esto se refiere al fomento de proyectos turísticos. En el multiculturalismo neoliberal mexicano, igual que en otros países latinoamericanos, el turismo indígena es fomentado y financiado no solo para incorporar a las comunidades indígenas rurales y marginadas al mercado turístico, sino

\footnotetext{
${ }^{5}$ En la misma línea, Claudia Briones y otros (2007) señalan cuatro tendencias del multiculturalismo neoliberal después de analizar casos argentinos: la puesta en valor de conceptos como poblaciones vulnerables, patrimonio, desarrollo sustentable; los vericuetos de la participación en un contexto de auto-responsabilidad que parte de asumir que todos sabemos todo y somos expertos de nosotros mismos; la diversificación de agencias y roles en un marco de cambio de empleadores; la transformación en las ideas de la política y lo político (Briones, et al., 2007: 279).
}

EntreDiversidades. Revista de Ciencias Sociales y Humanidades, Vol. 9, Núm. 1 (18), enero-junio 2022. Páginas: 148-175 ISSN-e: 2007-7610. https://doi.org/10.31644/ED.V9.N1.2022.A06 
también para transformar a los indígenas marginados en sujetos dóciles y performadores de su identidad, creando así al "indio permitido" (Rivera, 2016). ${ }^{6}$ Ciertamente, lo que se comercializa en el turismo indígena son las diferencias culturales, muchas veces exotizadas y esencializadas.

Por otra parte, como indican Hale (2004) y Jung (2003), la forma actual de gobernanza permite desarrollar la agencia política de los grupos culturales marginados y crear espacio donde estos articulan sus luchas con diferentes actores y organizaciones, pero "siempre que no acumulen suficiente poder como para cuestionar las prerrogativas básicas del Estado" (Hale, 2016: 19, traducción propia). ${ }^{7}$ En la actualidad, las movilizaciones y luchas indígenas siempre están articuladas con diferentes fuerzas, tanto desde arriba (los gobiernos, las instituciones gubernamentales, las organizaciones internacionales) como desde abajo (ONG, sociedad civil, Congreso Nacional Indígena, entre otros), entre las cuales, en el caso de los pueblos indígenas en la frontera, están las tribus estadounidenses que intentan dar una solución en conjunto a los problemas que enfrentan (véase más adelante).

En Estados Unidos, el multiculturalismo neoliberal, a pesar de sus consecuencias positivas, también tiene un lado oscuro. Primero, se trata del proceso de reconocimiento como nativo americano. A partir de los setenta, tras los movimientos del Red Power, el asunto del reconocimiento federal surgió en la escena nacional y la oficina de los Asuntos Indígenas (Bureau of Indian Affairs) creó el proceso para la obtención de reconocimiento federal (Federal Acknowlegment Process, FAP). El resultado fue que se hizo más estricto y complejo obtener dicho estatus (Miller, 2004), y, al mismo tiempo, la frontera entre los Native American reconocidos y los no reconocidos se hizo más marcada, concediendo los derechos a los primeros y excluyendo a los segundos. En otras palabras, estas reformas implicaron por un lado ampliar derechos y poder a los nativos americanos ya "reconocidos" por el Estado, y, por el otro, reducir considerablemente la posibilidad de que otros indígenas puedan conseguir el reconocimiento, ahora que ya está muy demandado y peleado. Miller, después de revisar varios casos concretos, concluye que el Estado sigue ejerciendo el poder hegemónico de definir la identidad racial, étnica y política de los indígenas en Estados Unidos (2004: 15) mediante el FAP.

Asimismo, la apertura de "etnoempresas" tiene problemas inherentes. Además de que el desarrollo económico con base en los casinos (locales de juegos de azar, espectáculos, entre otros) solo favorece a aquellos cuya reservación está ubicada en las cercanías de grandes ciudades, Comaroff y Comaroff (2009: 82) mencionan algunas problemáticas de estas etnoempresas, a saber: 1) pertenencia: establecida por la sangre y provoca procesos de inclusión-exclusión; 2) etnogénesis: el comercio produce y/o congela a un grupo étnico; 3) capital: el establecimiento del negocio tribal se pone en marcha con capital riesgoso procedente del exterior.

\footnotetext{
${ }^{6}$ Rivera lo define como "aquel que asume un papel ornamental en el nuevo Estado, y acepta recluirse en 'reservas étnicas' para representar papeles en la puesta en escena del 'turismo ecológico' o el 'turismo étnico' que haría incluso rentable una forma constreñida y teatral de la(s) identidad(es) indígena(s), convertidas en objetos exóticos de consumo" (2016: 67).

${ }^{7}$ Trad. propia: "[...] as long as it does not amass enough power to call basic state prerogatives into question" (Hale, 2016: 19).
}

EntreDiversidades. Revista de Ciencias Sociales y Humanidades, Vol. 9, Núm. 1 (18), enero-junio 2022. Páginas: 148-175 ISSN-e: 2007-7610. https://doi.org/10.31644/ED.V9.N1.2022.A06 
Ciertamente, las políticas del multiculturalismo neoliberal en Estados Unidos crean una “excepción” (Ong, 2006) (una nación soberana dentro del Estado-nación), en donde se les otorga un estatus particular y especial a los Native American, gracias al cual pueden exigir el territorio y los recursos, así como emprender negocios en la reservación con exención de impuestos. Pero, al mismo tiempo, la lógica neoliberal responsabiliza a estos pueblos de sus propios actos y decisiones como etnoempresa capaz de competir en el mercado global. Aunado a las políticas identitarias que abren espacios a los sujetos y grupos étnicos históricamente marginados y oprimidos de expresar y exigir su identidad cultural, se genera y se intensifica la dinámica de exclusión, y, por consecuencia, las fronteras entre los que tienen derechos y los que no los tienen se vuelven más rígidas que nunca.

Aunado a ello, las tribus o naciones cuya reservación está lejos de ciudades se ven obligadas a entrar a un mercado riesgoso, de desechos industriales o de extracción de recursos para su supervivencia, destruyendo asísu entorno y perjudicando la salud de sus miembros (Hanson, 2004). Lo peor es que estas actividades son entendidas como ejercicio de su soberanía política, y, además, la contención de los desechos industriales es posible por su "excepción”, ya que la reservación como territorio soberano tribal puede "dar acceso a los gobiernos y a las empresas para tratar algo que ha escapado a soluciones políticas y/o científicas adecuadas" (2004: 299, traducción propia). ${ }^{8}$ Sí es cierto que las reformas han proporcionado mayores oportunidades para la resistencia, la supervivencia y la autodeterminación de los Native American, pero, al mismo tiempo, aceleran su colonización y explotación (2004: 298). Hanson concluye:

Dentro de la emergente economía política neoliberal, se enfrentan ahora a una nueva contradicción mayor: cómo abrazar al bebé de alquitrán del nuevo capitalismo global como medio de autodeterminación económica, pero no dejar que ese paso se convierta en la cosa misma; no dejar que el desarrollo económico se convierta en la justificación predominante de la soberanía tribal; o incluso viceversa (2004: 302, traducción propia).?

Todo lo anterior sugiere que el multiculturalismo neoliberal, en general empodera a algunos y margina a la mayoría, a través de la concesión de (ciertos) derechos y la creación de sujetos y pueblos que se gobiernan a sí mismos de acuerdo con la lógica del capitalismo globalizado, en la cual el territorio y los recursos naturales se convierten en el medio para su desarrollo económico y en una mercancía. El ejercicio de autonomía o soberanía solo está permitido de acuerdo con la lógica de mercado neoliberal o limitado en el grado de que no perjudique el sistema político del Estado.

\footnotetext{
${ }^{8}$ Trad. propia: "[...] provide access to governments and corporations in dealing with something that has escaped (other) adequate political and/or scientific solutions in dominant society” (Hanson, 2004: 299).

${ }^{9}$ Trad. propia: "Within the emergent neoliberal political economy, they now face a new, perhaps larger contradiction: how to embrace the tar baby of new global capitalism as a means of economic self-determination but not let that step become the thing itself; not let economic development become the predominant justification for Indian sovereignty; or indeed, vice versa" (Hanson, 2004: 302).
}

EntreDiversidades. Revista de Ciencias Sociales y Humanidades, Vol. 9, Núm. 1 (18), enero-junio 2022. Páginas: 148-175 ISSN-e: 2007-7610. https://doi.org/10.31644/ED.V9.N1.2022.A06 


\section{El multiculturalismo neoliberal y las fronteras}

Como argumenté en el apartado anterior, el multiculturalismo neoliberal ofreció una oportunidad a la población indígena de ampliar su soberanía (en Estados Unidos) y de conseguir ciertos derechos culturales (en México), aunque con limitaciones, así como de intervenir en la arena política nacional para exigir sus demandas históricas. El proceso transnacional de los pueblos indígenas en la frontera coincide con la emergencia de la agencia indígena en el espacio transnacional, y conlleva el inicio de negociación constante con las fronteras tanto étnica como política. Aquí la transnacionalización se refiere a los intentos de atravesar la(s) frontera(s) a pesar de haberse incorporado en el sistema nacional como ciudadanos (estadounidense/mexicano) y como categoría sociopolítica (Native American/indígena), desde donde exigen sus derechos. En este apartado enfatizaré el papel de los Estados-naciones en la construcción de las fronteras bajo esta forma de gobernanza.

Las fronteras y las discrepancias son conceptos clave para entender el impacto de las políticas del multiculturalismo neoliberal hacia los indígenas: por un lado, la política de reconocimiento concede a los grupos étnicos cierto control y manejo de sus fronteras dentro de los límites preestablecidos, y, a su vez, los agentes étnicos elaboran estrategias para manipularlas y atravesarlas, o bien reforzarlas; por el otro, el Estado produce o aclara la frontera entre los permitidos y los radicales y entre los políticamente reconocidos y los políticamente no reconocidos, generando así la dinámica de exclusión, incluso dentro de la comunidad. En la era del multiculturalismo neoliberal, las diferencias reconocidas y fomentadas por las autoridades y las fronteras de pertenencia que se construyen dentro del grupo étnico son clave para entender los procesos dinámicos que ocurren en la zona transfronteriza.

En relación con los pueblos indígenas en la frontera, las políticas del multiculturalismo neoliberal no solo demarcan las fronteras arriba mencionadas, sino también refuerzan la frontera política, la comunitaria o tribal, así como la nacionalidad y la ciudadanía (mexicana o estadounidense), que afectan considerablemente en el cruce fronterizo. ${ }^{10}$ En Estados Unidos los ejercicios de la soberanía tribal en sí mismos producen procesos de exclusión, pues cada tribu oficialmente reconocida establece criterios propios de membrecía estipulados en la Constitución tribal y demarca la frontera entre miembros y no miembros. ${ }^{11}$ Bajo esta forma de gobernanza la frontera de pertenencia se vuelve cada vez más rígida y estática, mientras aumentan las demandas de inclusión; y el proceso de exclusión es más violento entre las tribus más exitosas en la etnoempresa. En México, si bien la dinámica de inclusión y exclusión es de otra índole, en algunas ocasiones la propia comunidad empieza a reconstruir una frontera comunitaria para salvaguardar ciertos derechos (véase el caso kumiai), o bien la mala distribución de recursos o derechos puede causar una división profunda interna (véase el caso yaqui). Además, las políticas multiculturales tienden a privilegiar a los ciudadanos pertenecientes al grupo étnico dominante, aumentando así la exclusión y explotación del resto de los indígenas (Reygadas, 2007: 348; Cañas, 2016).

\footnotetext{
${ }^{10}$ Esta diferencia también produce inequidad de derechos dentro de la sociedad dominante, incluso en las reservaciones. Para más detalles, véase Fukuma (2018).

${ }^{11}$ Cada tribu establece su propio criterio de membrecía y no existe un marco en común. La mayoría de las naciones o tribus pide como requerimiento tener como mínimo un cuarto de sangre tribal.
}

EntreDiversidades. Revista de Ciencias Sociales y Humanidades, Vol. 9, Núm. 1 (18), enero-junio 2022. Páginas: 148-175 ISSN-e: 2007-7610. https://doi.org/10.31644/ED.V9.N1.2022.A06 
Ahora bien, entre los pueblos indígenas transfronterizos está la frontera México-Estados Unidos, que no solo constituye el límite territorial entre dos Estados, sino también demarca la frontera política, cuya función es detener, separar y distinguir, con la capacidad de contener y filtrar los flujos que provienen del exterior (Bartolomé, 2008; Kearney, 2006). Asimismo, siendo tanto de institución como de proceso, esta frontera, como otras fronteras estatales, marca y delimita la soberanía y la ciudadanía individual — por ende, la construcción de las categorías "nacional" y "extranjero" - y tiene funciones en la creación y el mantenimiento del Estado nacional (Anderson, 1996, citado por Donnan y Wilson, 1999: 5). Así, a partir del establecimiento de la frontera internacional, en el interior de estos pueblos transfronterizos se selló una diferencia fundamental, la nacionalidad y la ciudadanía que no solo afecta la movilidad espacial, sino también la pertenencia e identidad. Esta diferencia se acentúa más con las políticas neoliberales y la militarización de la frontera.

Además, se han instituido gradualmente las diferencias y discontinuidades a partir del establecimiento de la frontera internacional; lenguas, construcciones sociales de etnicidad, sistemas educativos y escolares, sistemas políticos económicos, etc. Así, la instauración de la frontera implicó y sigue implicando una transformación del marco de significaciones y acciones de las poblaciones asentadas en la zona transfronteriza, entre quienes percibían y siguen percibiendo similitudes culturales.

El cruce fronterizo en la frontera México-Estados Unidos muestra la hegemonía del Estado en clasificar y filtrar personas y cosas que la atraviesan, o bien detenerlas completamente. Como ya se ha planteado en otros trabajos, la tarea de la frontera estadounidense no es detener el flujo de las personas y cosas de manera completa, sino de filtrar y categorizar a los que la atraviesan (Kearney, 2006); y de acuerdo con la identidad asignada, cambian drásticamente la velocidad, el derecho y el riesgo del cruce (Pallitto y Heyman, 2008). Además, la identidad asignada en la frontera determina su movilidad espacial y coadyuva a perseguir a los que intentan cruzar (Amoore, 2006); los que cruzan con permiso cultural permanecen en el territorio estadounidense en una posición ambigua, pues en cualquier momento su estatus legal puede ser cuestionado por la policía migratoria.

Esta situación empeoró a partir de la militarización de la frontera. Amoore (2006) y Pallitto y Heyman (2008) indican que con la implementación del biopoder fronterizo caracterizado por el US VISIT, ${ }^{12}$ el aparato de vigilancia y persecución se extiende a manos de los ciudadanos como responsabilidad social. Se trata de la disciplina y la interiorización de los discursos y los ejercicios antinmigrantes y terroristas a favor de la seguridad personal y nacional. En otras palabras, es una nueva forma de la gubernamentalidad en la cual cada ciudadano se encarga de protegerse a sí mismo de cualquier amenaza y forma parte de la securitización estatal a través de la manipulación del sentimiento de nosotros americanos compatriotas. Ahora, aparecen fronteras en cualquier

\footnotetext{
${ }^{12}$ La Tecnología de Indicadores de la Condición de Visitante e Inmigrante de los Estados Unidos (comúnmente conocida como US-VISIT) es un sistema de gestión de la Oficina de Aduanas y de Protección de Fronteras de los Estados Unidos (CBP) implementado en 2004. El sistema implica la colección y el análisis de datos biométricos (como las huellas dactilares), que se cotejan con una base de datos para rastrear a las personas que son consideradas terroristas, delincuentes e inmigrantes ilegales por Estados Unidos.
}

EntreDiversidades. Revista de Ciencias Sociales y Humanidades, Vol. 9, Núm. 1 (18), enero-junio 2022. Páginas: 148-175 ISSN-e: 2007-7610. https://doi.org/10.31644/ED.V9.N1.2022.A06 
parte del territorio estadounidense, y los más marginados o perjudicados por esta política, entre otros, son los sujetos de los pueblos transfronterizos.

Así, la frontera estadounidense, sobre todo a partir de su militarización, detiene el flujo constante y restringe la movilidad espacial y social de los pueblos indígenas en la frontera, sin importar si se es miembro o familiar de los integrantes de las tribus emparentadas en Estados Unidos. ${ }^{13}$ Además, como explican Pallito y Heyman (2008), cruzar con el permiso cultural (véase más adelante) produce diferentes tipos de inequidades: la inequidad de derechos — por ejemplo, en cuanto al derecho a estar libre de registros e incautaciones irrazonables, al derecho a la igualdad de trato frente a otras personas, etc.—; la inequidad de velocidad — por ejemplo, en la rapidez con que se produce el paso de frontera, más lento en el caso de los indígenas-; y la relacionada con el riesgo de ser revisados y discriminados, puesto que de acuerdo con su nacionalidad, clase social, raza y apariencia se los categoriza y perfila como sujetos con alto riesgo de convertirse en indocumentados.

No obstante, frente al endurecimiento y la militarización de la frontera, los pueblos indígenas fronterizos han luchado y han logrado establecer un acuerdo formal e informal con los agentes del Servicio de Inmigración y Naturalización (INS, Immigration and Naturalization Service) y el Servicio de Aduanas y Protección Fronteriza (CBP, U.S Customs and Border Protection) para que los sujetos indígenas del lado mexicano tengan el derecho al cruce fronterizo. Esto hace suponer que Estados Unidos reconoce los derechos de los indígenas mexicanos, en particular, el derecho a la movilidad transfronteriza para los pueblos indígenas fragmentados por la frontera, pero en realidad no es así (de hecho, Estados Unidos no ratifica el Convenio 169 de la Organización Internacional del Trabajo, OIT). Si bien algunos miembros de origen mexicano pueden cruzar la frontera y hacer visita en las reservaciones gracias a negociaciones constantes con los agentes de migración, esto no significa que el derecho de los indígenas mexicanos sea reconocido — para Estados Unidos son simplemente "mexicanos", o peor aún, mexicanos "pobres" que pueden convertirse en indocumentados—, sino que, más bien, se permite atravesar la frontera a condición de que las tribus estadounidenses, a pesar de ser una nación soberana dentro del Estado, respalden la identidad de quien la cruza y, en cierta medida, asuman la responsabilidad de retornar a los visitantes mexicanos al otro lado de la línea. Esto, al fin y al cabo, obliga a las tribus estadounidenses a controlar el flujo y colocar su propio filtro para poder mantener el acuerdo actual de cruce (para profundizar más, véase Fukuma, 2018).

Como vemos en el siguiente apartado, a pesar de las estrategias y tácticas formales e informales para superarla o atravesarla, la frontera México-Estado Unidos constituye una barrera enorme. Sobre todo, después del 11 de septiembre el endurecimiento de las políticas migratorias dio un golpe fuerte a estos pueblos, pidiéndoles más documentaciones y dejando la responsabilidad de cualquier irregularidad a las tribus emparentadas en Estados Unidos. Aquí observamos otro ejemplo de "excepción”, el ejercicio de soberanía de las tribus estadounidenses, pero responsables

\footnotetext{
${ }^{13}$ Esto queda muy claro en el caso de los Tohono $O$ 'odham, que a pesar de que la nación Tohono O'odham otorga membrecía a los tohono o'odham de la nacionalidad mexicana, estos siguen sufriendo hostigamiento injusto y violencia de parte del border patrol y agentes de migración (Luna-Firebaugh, 2002).
}

EntreDiversidades. Revista de Ciencias Sociales y Humanidades, Vol. 9, Núm. 1 (18), enero-junio 2022. Páginas: 148-175 ISSN-e: 2007-7610. https://doi.org/10.31644/ED.V9.N1.2022.A06 
de los miembros provenientes del lado mexicano mientras permanecen en el país norteño. Sin duda, esto forma parte de las políticas del multiculturalismo neoliberal.

Con la nueva gubernamentalidad, los pueblos transfronterizos, siendo población heterogénea y diferenciada en el marco nacional y dispersa en la zona transfronteriza, enfrentan nuevos retos y problemas, colocándose en el entreverado de una nueva y compleja configuración de relaciones de poder.

\section{Dos casos: los yaquis y los kumiai/Kumeyaay}

Desde los noventa, los pueblos indígenas yaquis y kumiai/Kumeyaay han reforzado los lazos familiares y étnicos más allá de la frontera internacional y de otras políticas y culturales. Este proceso nuevo de transnacionalización se inició por la iniciativa de las tribus estadounidenses que han logrado ampliar su soberanía en el país, y, con ello, avanzar al espacio transnacional con la intención de superar los marcos nacionales y las categorías nación-centristas, así como desafiar al poder.

Como la dinámica transfronteriza produce procesos étnicos específicos, propios de una relación asimétrica en términos económicos y de derechos políticos (Olmos, 2007: 29), existen diferencias y discrepancias entre los individuos y las comunidades situados en ambos lados de la frontera. En el caso de los yaquis y los kumiai/Kumeyaay, los individuos pertenecen a dos Estados-naciones diferenciados y a distintas comunidades, tribus o pueblos, por lo que no solo existen las fronteras políticas y socioculturales, sino también una notable disparidad económica-política entre ellos. A diferencia de otros pueblos indígenas transnacionales, entre estos pueblos transfronterizos no existe una organización o asociación transnacional en la que participen los miembros de ambos lados de la frontera; no obstante, entre los territorios étnicos hay personas, familias y organizaciones que se conectan y se articulan entre sí. El intercambio transfronterizo y transnacional principalmente se centra en la esfera ritual y cultural, y mediante el intercambio de dones se tejen relaciones de ayuda mutua y se construye una identidad cultural y política que rebasa las fronteras. Asimismo, este proceso estimula el surgimiento de una nueva configuración cultural, como resultado de la apropiación cultural o transcultural en el contexto dinámico transfronterizo (Olmos, 2007; Fukuma, 2018).

Es importante destacar que aunque las prácticas transfronterizas y transnacionales tienen como objetivo principal la reproducción de la cultura e identidad a través del intercambio cultural, lo hacen porque son de "una" nación, una familia que fue violentamente dividida y fragmentada por el establecimiento de la frontera y los Estados modernos, así como por las políticas migratorias y de asimilación. La frase "no cruzamos la frontera, la frontera nos cruzó a nosotros", tal y como la declaran, muestra claramente su experiencia de la fragmentación forzada — tanto familiar como territorial — y el apuro histórico, así como su deseo de reorganizar y recuperar lazos familiares más allá de la frontera. En otras palabras, la transnacionalización está sustentada por el pensamiento decolonial de poder, en el cual estos pueblos empiezan a imaginar una nación libre de fronteras nacionales y nación-centristas y construir una nueva identidad cultural y política, capaz de desafiar al Estado y otras fuerzas abrumadoras, y, con ella, agendar 
las prácticas culturales y políticas que posibilitan articular la población y los espacios étnicos divididos por la frontera. Sin embargo, debido a la existencia de la frontera hegemónica están atrapados en el complejo entreverado del poder y enfrentan las diferencias tanto institucionales como culturales producidas y acentuadas a lo largo del tiempo, lo que dificulta comunicarse de manera fluida y reorganizarse para construir "una" nación sin fronteras.

\section{Yaqui}

Si bien la demarcación original de los yaquis, conocida como el Territorio Yaqui, se sitúa en el sur del estado de Sonora, actualmente sus territorios y espacios (enclaves) étnicos se extienden en ambos lados de la frontera internacional como resultado de la movilidad (muchas veces forzada) a lo largo de la historia. Tradicionalmente, los yaquis se movían en una vasta zona por el intercambio comercial con otros pueblos, por lógica de la misión jesuita o por búsqueda de trabajo, pero la movilidad masiva comienza durante el Porfiriato y la Revolución Mexicana, causada por las violencias sistematizadas del Estado mexicano; la persecución y deportación de los yaquis les obligó a salir de su territorio y atravesar la frontera internacional (Hu-DeHart, 1984; Padilla, 1995, 2009; Spicer, 1994; Fukuma, 2018). ${ }^{14}$ Como resultado de la movilidad forzada, existen varios territorios y espacios étnicos a lo largo de la región Sonora-Arizona (incluso fuera de ella, como en California, Texas, en Estados Unidos y Baja California, en México, entre otros). Sin embargo, el intercambio familiar y ceremonial más allá de la frontera siguió produciéndose de forma irregular, aunque cada vez de manera menos frecuente en el transcurso de tiempo (para más detalles, véase Fukuma, 2018). El cambio decisivo vino en 1978, cuando los yaquis en Estados Unidos recibieron el reconocimiento federal como Native American. Esto implicó la completa separación política de los yaquis en México a través de la creación de la membrecía tribal, ${ }^{15}$ excluyendo no solo a los yaquis de nacionalidad mexicana, sino también a los yaquis nacidos en Estados Unidos que no pueden comprobar los requisitos para la membrecía, el porcentaje de "sangre" yaqui.

No obstante, tener estatus legal y político como Pascua Yaqui Tribe (PYT) les permitió no solo tener territorio, la reservación donde se gobiernan por sí mismos y expresan abiertamente la identidad étnica que durante mucho tiempo fue oprimida, sino también recuperar los lazos perdidos con los yaquis en el lado mexicano, así como revitalizar algunas prácticas culturales y rituales con ayuda de estos. Gracias a ello, actualmente existen múltiples conexiones étnicas a lo largo de Sonora-Arizona, por las cuales se circulan objetos, capital, símbolos, servicios, así como información. Es decir, ahora se desarrolla el sistema de intercambio de dones entre las comunidades de Arizona y los pueblos de Sonora, consolidado principalmente en el ámbito

\footnotetext{
${ }^{14}$ Cabe mencionar que una de las razones por las cuales los yaquis en Estados Unidos fueron reconocidos como Native American fue por el documento histórico archivado en la antigua misión Tumacácori, ubicada en el sur de Arizona, que comprueba la presencia de familias yaquis en dicho lugar antes del establecimiento de la frontera internacional.

${ }^{15}$ Los criterios de membrecía de la Pascua Yaqui Tribe (PYT) son: 1) ser un descendiente directo o un pariente colateral de un miembro de sangre yaqui, 2) poseer al menos un cuarto de sangre yaqui, y 3) ser ciudadano de los Estados Unidos.
}

EntreDiversidades. Revista de Ciencias Sociales y Humanidades, Vol. 9, Núm. 1 (18), enero-junio 2022. Páginas: 148-175 ISSN-e: 2007-7610. https://doi.org/10.31644/ED.V9.N1.2022.A06 
ritual. Asimismo, a partir de la década de los noventa, la apertura de los negocios tribales en la reservación le posibilitó ampliar la soberanía, ${ }^{16} \mathrm{y}$, con ello, extender su influencia en la zona transfronteriza para agilizar el cruce transfronterizo e intervenir en problemas que enfrentan los yaquis ubicados en Sonora — problemas de territorio y recursos naturales-.

El desarrollo del intercambio transnacional vino de una necesidad inherente, pero no habría sido posible sin los cambios ocurridos durante las últimas décadas en Estados Unidos y México: uno de ellos es, sin duda, el reconocimiento federal como Native American. El año 1978 fue cuando se estableció el proceso de reconocimiento federal (FAP) y, al mismo tiempo, cuando los yaquis fueron reconocidos como Native American por vía legislativa; justamente, los yaquis fueron los últimos en recibir el reconocimiento federal antes de su implementación.

A partir de este momento, la PYT ha crecido de manera muy acelerada y ha conseguido algunos logros políticos a través de las negociaciones con los gobiernos estatal y federal sin sobrepasar el margen de lo permitido. Asimismo, el gobierno tribal logra mostrar su presencia dentro de los Native American en Arizona y utilizar proyectos pioneros para el ejercicio de su soberanía. Por ejemplo, la PYT entró en el negocio de los juegos de azar en los ochenta y ahora cuenta con dos casinos, un hotel de cuatro estrellas, una sala de conciertos, una tienda de tabaco y un campo de golf. El desarrollo del negocio tribal mejoró la condición de vida de muchos yaquis, y permitió invertir en la mejora de la infraestructura y servicios en sus territorios, así como en la cultura y la educación. En la reservación hay un preescolar y una preparatoria, así como el Yoemem Tekia Cultural Center (Museo y Centro Cultural "Yoemem Tekia") y el Departamento de Lengua y Cultura, donde se enseñan la lengua vernácula, la historia étnica, música y danza tradicional. En el campo político, la PYT es la primera tribu que logró conseguir la "Enhanced Tribal ID Card" como tarjeta de identificación tribal y como border crossing card. Esta tarjeta permite a los miembros de la PYT cruzar las fronteras tanto de México como de Canadá por vía terrestre y marítima sin necesidad de portar el pasaporte.

Tocante a los yaquis en México, las políticas del multiculturalismo neoliberal han traído consecuencias negativas: despojo de territorios y recursos naturales, división interna provocada por megaproyectos y proyectos de autogestión, así como dependencia de los proyectos económicos ofrecidos por las instituciones gubernamentales y/o las empresas transnacionales. Tras la Guerra Yaqui, el presidente Cárdenas ejecutó la restitución de casi la mitad del territorio ancestral y reconoció derechos a la autonomía y los recursos naturales (Spicer, 1994). Sin embargo, a partir de la década de los sesenta se aceleró el proceso de incorporación a la estructura nacional, sobre todo en el sector de producción y educación; las instituciones gubernamentales empezaron a controlar considerablemente la vida de los yaquis (Spicer, 1994). El proyecto del Plan Integral de Desarrollo de la Tribu Yaqui (PIDTY) (1982-1997) surgió como respuesta a las exigencias de liberarse de la influencia y el control de las instrucciones del gobierno (de Banrural y de la Secretaría de Agricultura y Recursos Hidráulicos) en la producción agrícola y recuperar la autonomía económica. El PIDTY como proyecto de autogestión dio inicio a 48 programas y casi 20 proyectos, pero, al final, provocó una división dentro de los pueblos yaquis debido a los

\footnotetext{
${ }^{16}$ En los noventa también hubo otro cambio importante, el de estatus político de "created tribe" a "bistoric tribe", que les permitió a los yaquis autodeterminarse y tener jurisdicción en su territorio (Castile, 2002).
}

EntreDiversidades. Revista de Ciencias Sociales y Humanidades, Vol. 9, Núm. 1 (18), enero-junio 2022. Páginas: 148-175 ISSN-e: 2007-7610. https://doi.org/10.31644/ED.V9.N1.2022.A06 
violentos cambios de la estructura tradicional de poder y el surgimiento de otros actores (Lerma, 2015). Esta fragmentación, además, tuvo impacto en las relaciones entre la tribu yaqui y los gobiernos estatal y federal, puesto que el gobierno dio por sentado que no existían condiciones para negociar con la tribu (2015: 300).

Otro acontecimiento que sacudió a la tribu yaqui y repercutió en la arena nacional fue la construcción del Acueducto Independencia con la intención de canalizar el agua de la presa Novillo a Hermosillo, donde la escasez de la misma constituye un problema crítico. Este megaproyecto enfrentó la resistencia fuerte tanto de los yaquis como de otros actores sociales, ya que la construcción de la obra no fue informada y consensuada de manera correcta con la población afectada. Unos meses después del inicio de su operación, los yaquis, junto con los integrantes del Movimiento Ciudadano por el Agua, se pusieron en acción para detenerla e iniciaron un bloqueo sobre la Carretera Internacional México 15. Gracias a la articulación con las ONG, las universidades y las organizaciones civiles, esta movilización se transformó en una pugna mediática y una suma de las luchas contra el despojo de los recursos naturales. La táctica de bloquear la Carretera Internacional México 15 fue una forma eficaz de hacer escuchar sus demandas al gobierno y obligarle a sentarse a la mesa de diálogo para solucionar el problema, ya que la detención del flujo de mercancías a Estados Unidos causó grandes perjuicios a la economía nacional y transnacional, la mayor contraparte de la exportación de los productos nacionales. A pesar de las resistencias prolongadas y la sentencia de amparo por la Suprema Corte de Justicia de la Nación, a fin de cuentas, se validó la operación del acueducto en 2015; y ahora, el problema gira en torno a la construcción del gasoducto que atraviesa su territorio.

Por otra parte, hay otros proyectos de autogestión en el sector productivo que inició el gobierno de Partido Acción Nacional (PAN). Por un lado, el proyecto de invernadero en la Loma de Guamúchil (Cócorit Produce) y Tórim (Tórim Produce) para la producción agrícola destinada para la exportación a Estados Unidos y Canadá. Por el otro, el proyecto turístico, Parador Turístico Yaqui, construido al lado de la carretera internacional 15 a la altura de Loma de Guamúchil, donde se suponía que se ofrecería la venta de artesanía y comida tradicional yaquis. Sin embargo, este último actualmente está detenido por la Autoridad Tradicional del mismo pueblo por falta de cumplimiento de sus demandas. Las pretensiones del gobierno estatal se entrevén en estos proyectos: en primer lugar, incorporar a los yaquis a la economía nacional como organización autogestora o como emprendedor, utilizando la alta tecnología y aprovechando la cercanía con Estados Unidos; en segundo lugar, incentivar el turismo a través de la promoción de la representación cultural — de hecho, se construyó una estatua gigante de un danzante de venado- como grupo étnico resistente con una cultura muy "auténtica". En palabras de Hale (2016), se trata de convertirlos de "indios rebeldes" a "indios permitidos", aunque no se alcance el resultado esperado.

En la actualidad, todos los asuntos que la tribu yaqui ha exigido durante siglos y décadas pasadas siguen sin resolverse, excepto los apoyos a proyectos de autogestión. Además, los yaquis trabajan cada vez más fuera de su territorio, en maquiladoras en las ciudades cercanas o campos agrícolas, e incluso los jóvenes migran temporalmente al norte del estado en busca de mejores condiciones de trabajo y de sueldo.

EntreDiversidades. Revista de Ciencias Sociales y Humanidades, Vol. 9, Núm. 1 (18), enero-junio 2022. Páginas: 148-175 ISSN-e: 2007-7610. https://doi.org/10.31644/ED.V9.N1.2022.A06 
No obstante, el multiculturalismo neoliberal abrió espacios para la reorganización étnica. La transnacionalización alcanzó su auge en los años noventa, en los cuales surgieron varias ideas y proyectos para reforzar los lazos étnicos y encarnar "una” nación sin frontera. A partir de ahí, se intensificó el intercambio transnacional, sobre todo en el ámbito ritual y cultural. Una de las características, sin duda, es la participación de los yaquis de origen mexicano en los rituales celebrados en comunidades de Arizona, creando así lazos muy estrechos y de ayuda mutua entre los yaquis de ambos países. Cabe destacar que en este proceso, gradualmente se han ido formando las familias transnacionales y las relaciones de parentesco espiritual (compadrazgo y padrinazgo) entre los yaquis de diferentes nacionalidades, pueblos y pertenencias, a través de la recuperación de los lazos de parentesco y/o la renovación de estos, o bien por el establecimiento de compromisos rituales (Fukuma, 2018).

Por otra parte, el don transnacional se ha extendido y se ha diversificado en el tiempo y el espacio. Los individuos, familias y diferentes organizaciones en Arizona coordinan de manera irregular apoyos caritativos y envían víveres, ropa usada y materiales escolares a las familias y pueblos yaquis más necesitados. Estos apoyos no transforman la situación económica de los pueblos yaquis sonorenses pero sí ayudan de alguna forma a cubrir necesidades y salir de apuros.

En cuanto a la erradicación de la pobreza, dar una solución adecuada es algo complicado y complejo ante la necesidad urgente de crear medios de producción y fuentes laborales en Territorio Yaqui, más que el don caritativo. De hecho, hubo varios intentos para mejorar la situación económica de los pueblos yaquis sonorenses a través del apoyo de los yaquis de Arizona mediante la comercialización de carbón y camarón, pero dejó de funcionar debido a dificultades de coordinación y, sobre todo, por la discrepancia en las maneras de trabajar y diferencias estructurales entre las dos partes (para más detalles, véase Fukuma, 2011). Ahora solo se ofrecen los apoyos jurídicos para las luchas por tierras y recursos naturales que están en proceso en Territorio Yaqui. Además, una de las barreras para crear vínculos más sólidos y funcionales es la división existente en los ocho pueblos tradicionales, provocada por el PIDTY y luego agravada por el Acueducto Independencia, pues la PYT evita tomar partido para no intervenir en los asuntos políticos internos.

Por último, respecto al cruce transfronterizo, los yaquis han conseguido este derecho desde hace décadas. Como mencioné anteriormente, para reforzar los lazos étnicos es fundamental facilitar el cruce transfronterizo de personas y cosas, de manera bidireccional. Desde los años sesenta, los yaquis arizonenses negocian constantemente con los agentes de migración para que los yaquis mexicanos puedan visitar las comunidades emparentadas en Estados Unidos. Uno de los logros importantes entre los yaquis fue introducir y establecer el sistema de permiso cultural para el cruce fronterizo de los miembros mexicanos. La necesidad surgió de repente cuando los agentes empezaron a pedir documentos oficiales a los participantes mexicanos. El capitán de San Martín de Porres relata: 
Pero cuando me empezaron a mandar a Río Yaqui, ${ }^{17}$ a convidar a los pascolas y maso [venado], ${ }^{18} \mathrm{y}$ me di cuenta de que había muchos requisitos, necesitaba pasaporte para cruzar la frontera, y [...] estaba difícil, aparte de todo eso, cobraban para pasaporte, y pensaba yo, ¿por qué necesitamos pasaporte para todo esto?, somos yaquis, tenemos pariente acá y allá, [...], para ver la ley que nos impone, [...], pues se me hizo difícil por primera vez [...] y ahí [en la oficina de migración] me quedé todo el día, rogando a los oficiales ahí, hasta que me mandaron al director y me estaba platicando con él y por qué llegaba la gente para aquí, [...], y me dijo: "vamos a poner a quien encargar, vas a asegurar que esta gente, lo que tú dices y asegurar que va a regresar, que no se va a quedar, y tú vas a asegurarlo". Así que, no más dos [personas] tenían pasaporte, eran 12, y los demás no tenían nada, entonces, [el director] dice: "vas a convidar a la gente que no tiene documento en el consular americano en el Hermosillo". Era una lista de gente que traigo, de dónde son, a dónde van, y a qué van. [...] Entonces con el permiso todos llegan acá, y así pasó. Y llegué con ellos, todos yaquis a participar en la Cuaresma, desde entonces empecé haciendo ese trabajo, y ahora ya tiene un sistema, ya está aceptado y adoptó la Pascua, porque aquel tiempo no había la tribu (capitán de San Martín de Porres, Barrio Libre, entrevista en 2014).

El nacimiento de la PYT facilitó la comunicación con los agentes de migración, lo que favoreció el surgimiento de una nueva forma para el cruce fronterizo, la visa láser. Así, gracias al acuerdo con los agentes de la frontera (el INS), la visa se entrega únicamente a los yaquis mexicanos con años de participación en los rituales y todo el costo es cubierto (tanto el de pasaporte mexicano como el de visa) por el gobierno tribal. Por esta razón, a diferencia de los kumiai, entre los yaquis son muy escasos los portadores de la visa, aunque el cruce fronterizo con el permiso cultural es posible y frecuente para asistir y participar en eventos culturales. Sin embargo, la situación cambió después de 2016 con la llegada del gobierno de Trump. Durante su cuatrienio, la mayoría de las veces dejaron de utilizar el permiso cultural para mantener buenas relaciones con el CBP y para que no se anule el acuerdo por cualquier irregularidad. Además, quedándose en uno de los estados con fuerte rechazo a los inmigrantes, Arizona, los yaquis con el permiso cultural se encuentran atrapados en la comunidad de acogida sin poder salir de ella durante su estancia (que a veces dura más de 40 días) (Fukuma, 2018).

\section{Kumiai/Kumeyaay}

Los kumiai/Kumeyaay son un grupo étnico cuyo territorio ancestral se extiende por la parte meridional de California, Estados Unidos, y la septentrional de Baja California, México. ${ }^{19}$ En la actualidad hay trece tribus reconocidas por el gobierno federal en California mientras en Baja

\footnotetext{
${ }^{17}$ Río Yaqui es como se conoce al Territorio Yaqui en el lado fronterizo estadounidense.

${ }^{18}$ Las danzas de los pascolas y el maso tienen origen prehispánico y representan juya ania (mundo del monte) y yo ania (mundo antiguo y venerable). Ambas danzas son indispensables para toda ritualidad yaqui (excepto la Cuaresma).

${ }^{19}$ Utilizo dos términos para referirme al grupo étnico dependiendo del lado donde se encuentra: "kumiai” es referido a los que se encuentran en el lado mexicano, por ende, con la nacionalidad mexicana, mientras que Kumeyaay alude a los que habitan en el lado estadounidense, con la nacionalidad estadounidense.
}

EntreDiversidades. Revista de Ciencias Sociales y Humanidades, Vol. 9, Núm. 1 (18), enero-junio 2022. Páginas: 148-175 ISSN-e: 2007-7610. https://doi.org/10.31644/ED.V9.N1.2022.A06 
California existen cinco comunidades. El establecimiento de la frontera internacional no solo dividió su territorio, sino también a sus familias: las que se asentaban en el lado estadounidense se convirtieron en estadounidenses y las que se encontraban en el otro lado de la frontera, en mexicanas. Los procesos de integración al sistema nacional y el desarrollo económico de la zona trajeron una reducción importante de su territorio en ambos países, y, con ello, los kumiai/Kumeyaay se vieron obligados a sedentarizarse en pequeñas extensiones de tierra o modificar constantemente su residencia a lo largo del tiempo por el avance de los colonos.

Originalmente, los kumiai/Kumeyaay estaban organizados por linajes y su medio de subsistencia era la caza, la pesca y la recolección (Garduño, 2016). Antes de su sedentarización, este grupo étnico vivía en movimiento, dependiendo de la temporada, entre la costa del Pacífico, las montañas y cerca del río Colorado (Garduño, 2014b; Magaña, 2010), y el territorio de cada linaje se extendía más allá de la frontera. Hacia finales del siglo XX no solo había un flujo de personas, sino también intercambios comerciales, culturales y sociales más allá de la frontera (Shipek, 1991; Garduño, 2004, 2014a; Santiago, 2006). ${ }^{20}$

A partir de los noventa, los Kumeyaay han experimentado un cambio drástico. La mayoría de las tribus Kumeyaay entró en el negocio de los casinos, que ha tenido un éxito significativo gracias a la cercanía a San Diego. De hecho, Viejas Band of Kumeyaay Indians, Sycuan Band of the Kumeyaay Nation y Barona Band of Mission Indians son varias de las tribus más exitosas del Sur de California. No obstante, no todas las tribus han triunfado en los negocios tribales; por ejemplo, el casino de Iipay Nation of Santa Ysabel quebró en 2014 después de varios años de operación debido a la distancia geográfica, y ahora intenta emprender un nuevo proyecto, la producción y venta de marihuana (Jones, 2017). El ingreso proporcionado por los casinos y otros negocios tribales permite desarrollar la infraestructura en la reservación y ampliar servicios, así como invertir más en la educación y la preservación cultural, uno de los más importantes elementos para la reconstrucción de identidad. En 2004 se fundó Kumeyaay Community College donde se imparte la lengua Kumeyaay, etnoecología, arte y cultura étnica y etnohistoria reescrita e interpretada por ellos mismos, así como Sycuan Cultural Resource Center and Museum abierto en 2016, donde exhiben, además de artefactos y artesanías étnicos, colecciones y archivos de la estudiosa de la etnia Florence Shipek.

En cambio, en Baja California, igual que los yaquis, a partir de las políticas neoliberales se iniciaron varios proyectos de autogestión encaminados al turismo, a saber, el ecoturismo —en San Antonio Necua y San José de la Zorra-y la producción de artesanía. En cuanto al primero, impulsado desde hace décadas por el gobierno mexicano "con el fin de contribuir al desarrollo de la población indígena por medio de apoyos para elaborar y ejecutar proyectos encaminados al aprovechamiento sustentable de sus bellezas naturales y patrimonio cultural" (Palomino y López, 2007: 55, citado en Herrera, 2016: 3), se inició por la necesidad de generar empleo dentro de la comunidad. Situadas alrededor de la Ruta del Vino, San Antonio Necua y San José de la Zorra no gozan de este crecimiento turístico, aunque sí es cierto que los miembros

\footnotetext{
${ }^{20}$ Un caso muy ilustrativo es el de Delfina Cuero (1900-1972), quien nacida en Jamacha, California, vivía en movilidad en la zona transfronteriza con su familia para su supervivencia y por la presión de los colonos que cada vez más llegaban a California. Para más detalles, véase Shipek (1991).
}

EntreDiversidades. Revista de Ciencias Sociales y Humanidades, Vol. 9, Núm. 1 (18), enero-junio 2022. Páginas: 148-175 ISSN-e: 2007-7610. https://doi.org/10.31644/ED.V9.N1.2022.A06 
están incorporados a esta industria no como empresarios sino como jornaleros. De la misma manera, con miras a incentivar la potencialidad económica y erradicar la pobreza, desde los ańos ochenta les proporcionan apoyos e incentivos para la producción de artesanía; por un lado, se ofrecen talleres artesanales impulsados por el gobierno estatal y, por el otro, se celebra el concurso del Fondo Nacional para el Fomento de las Artesanías (FONART), en el cual cada año algún miembro de los kumiai gana en la categoría de cestería.

A lo largo de este proceso, la artesanía kumiai ha ido cobrando un valor, no solo identitario - la artesanía como símbolo de identidad—, sino también económico, como una manera de subsistencia; y, como consecuencia, se han revivido algunos diseños típicos de los kumiai y surgido nuevos a través de la resignificación de sus narrativas (Garduño, 2014a), así como se han creado nuevos productos destinados a los turistas que antes no eran fabricados en las comunidades kumiai (por ejemplo, jabones, collares, entre otros). ${ }^{21}$ Si bien el turismo suele estar vinculado con la idea de transformar las tradiciones indígenas, e incluso, destruir su "autenticidad" través de la mercantilización, no hay que olvidarse del proceso de reapropiación y la agencialidad de los actores indígenas en el contexto inevitable del fenómeno turístico que se basa y se consolida en las relaciones asimétricas de poder (Ota, 1998: 70). De acuerdo con Ota, en la industria de turismo ocurre "la objetivación de cultura", recreación de la cultura como objeto manipulable a través de la selección, interpretación y resignificación de los elementos culturales (1998: 72). Desde este enfoque, el caso kumiai es buen ejemplo de cómo los indígenas negocian y reconstruyen la identidad en el contexto del turismo.

La incorporación a la industria turística y la promoción de las culturas nativas ${ }^{22}$ por sí mismas no erradican la pobreza y a veces generan conflictos internos y desigualdades, pero sí proporcionan la oportunidad tanto para reconstruir la identidad cultural y política como de reforzar y revitalizar las prácticas y los intercambios culturales más allá de las fronteras geográficas y comunitarias o tribales. Asimismo, cabe señalar que en este proceso se refuerza la identidad yumana, o mejor dicho, "nativa": no solo se pertenece a una comunidad o etnia, sino también se es yumano/nativo, el conjunto de los pueblos indígenas que derivan de la rama lingüística yumano-cochimí y que habitan desde el tiempo remoto en el actual California, Baja California y partes de Arizona y Sonora. Si bien esta reorganización se debe también a fuerzas externas, tales como instituciones gubernamentales y los académicos, en el resurgimiento de la identidad indígena los propios actores étnicos se identifican con "nativo" y se organizan en conjunto para exigir sus demandas y para reforzar las conexiones de ayuda mutua y de intercambio. Actualmente, se realiza el reencuentro cultural llamado "Na Ojap Santa Gertrudis" bajo la iniciativa de jóvenes yumanos de diferentes sitios a lo largo de Baja California con el objetivo de "recorrer su territorio y recuperar huellas ancestrales por toda la península” (anónimo, publicado en Facebook, el 3 de marzo, 2020). Además, esta articulación yumana no solo se limita al nivel nacional, sino también transnacional;

\footnotetext{
${ }^{21}$ Garduño (2014a: 13) menciona que, según Owen y Hinton, en los años cincuenta registraron la desaparición de la práctica de la cestería y la ausencia de decoración alguna en aquellas piezas que llegaban a encontrarse en restos arqueológicos.

${ }^{22}$ Los yumanos utilizan el término "nativo/nativa" para diferenciarse de los indígenas migrantes que se encuentran hoy en Baja California, tales como los mixtecos, los zapotecos, los purépechas, etc.
}

EntreDiversidades. Revista de Ciencias Sociales y Humanidades, Vol. 9, Núm. 1 (18), enero-junio 2022. Páginas: 148-175 ISSN-e: 2007-7610. https://doi.org/10.31644/ED.V9.N1.2022.A06 
desde hace dos décadas se organiza el Yuman Language Family Summit en Estados Unidos, con la intención de revitalizar la lengua mediante las tradiciones, la historia, la espiritualidad, las canciones y los cuentos (Yuman Language Family Summit, s.f.), en el cual participa un grupo yumano del lado mexicano. En esta articulación nacional y transnacional, el CUNA (Instituto de Culturas Nativas de Baja California), ${ }^{23}$ una ONG que trabaja para los pueblos indígenas de Baja California, ha jugado un papel central como vínculo con las instituciones gubernamentales y con las tribus estadounidenses, a cargo de la distribución de la información y del apoyo nacional y transnacional.

Por otra parte, desde el establecimiento de los Estados modernos, el despojo territorial y de recursos naturales, así como la protección de los lugares sagrados, son unos de los problemas centrales para los kumiai/Kumeyaay. En Estados Unidos la reasignación forzosa de los residentes de la reservación de Capitán Grande — uno de los sitios sagrados para los Kumeyaay — para construir la presa es conocida como la última reubicación de American Indian (1931) sin que los habitantes fueran suficientemente recompensados por el daño (Banegas, 2017). En cambio, la situación en México aún es más grave, pues existe el despojo territorial y los problemas territoriales y de recursos en todas las comunidades kumiai: el más conocido es el de la vitivinícola L.A. Cetto, que invadió 80 hectáreas de la comunidad de San Antonio Necua. Por último, la construcción de los muros fronterizos afecta considerablemente a los paisajes y a los sitios sagrados como la montaña Cuchumá, así como a sus memorias étnicas relacionadas (Garduño, 2014b). Como comenta una activista kumiai (entrevista en noviembre, 2018), a pesar de que los kumiai/Kumeyaay se han movilizado y han hecho protestas contra la construcción de vallas metálicas, sus voces no han sido escuchadas ni atendidas por ambos gobiernos.

Desde la década de los noventa, se han iniciado diversos intercambios transfronterizos (es decir, las fronteras comunitarias y tribales) y transnacionales principalmente en el ámbito cultural. En este acercamiento, si bien viene de la necesidad de los propios indígenas de revitalizar la lengua y las tradiciones, estaban involucradas las instituciones académicas y gubernamentales que empezaron a organizar encuentros yumanos binacionales a partir de los años ochenta. Posteriormente, por la iniciativa de los propios indígenas, el intercambio transnacional se hizo más frecuente y sistemático (Mike Wilken, entrevista en diciembre, 2018). ${ }^{24}$ Por la dispersión de los espacios étnicos y de su población — teniendo en cuenta que existen 18 reservas/comunidades de manera dispersa en la zona transfronteriza y muchos miembros viven fuera de las reservaciones/comunidades_-, los festivales y eventos culturales ofrecen una oportunidad para los diversos tipos de intercambio transfronterizo y transnacional entre los kumiai/Kumeyaay divididos por las fronteras. En la actualidad, el intercambio cultural transnacional tiene lugar en diferentes espacios y tiempos; por ejemplo, la reservación de Campo Kumeyaay Nation en California invita a los

\footnotetext{
${ }^{23}$ El CUNA es fundado por el antropólogo estadounidense Michael Wilken, junto con personas indígenas y no indígenas. Actualmente esta organización es administrada y dirigida por jóvenes nativos y trabaja principalmente en cuatro programas: salud, educación, cultura y desarrollo sustentable.

${ }^{24}$ Wilken relata que el primer trabajo del CUNA acerca del intercambio transnacional fue cuando la tribu Yavapai de Prescot, Arizona, quiso invitar a los paipai de Baja California a su reservación. De la comunidad paipai llevaron diez u once personas indígenas, junto con unos traductores de inglés-español, ya que no todos hablaban la lengua vernácula (entrevista en diciembre, 2018).
}

EntreDiversidades. Revista de Ciencias Sociales y Humanidades, Vol. 9, Núm. 1 (18), enero-junio 2022. Páginas: 148-175 ISSN-e: 2007-7610. https://doi.org/10.31644/ED.V9.N1.2022.A06 
hablantes de kumiai de México para revitalizar la lengua kumiai ${ }^{25}$ también invitan a los cantantes y danzantes a los festivales celebrados en las reservaciones y las comunidades de ambos lados de la frontera (por ejemplo, fiestas de reconocimiento, powwow, fiestas patronales, fiesta nativa, ${ }^{26}$ etc.). El antropólogo y fundador del CUNA, Michael Wilken, afirma que estos intercambios permiten descubrir conexiones de linaje perdidas durante mucho tiempo y revitalizar las prácticas tradicionales de manera conjunta (entrevista en diciembre, 2018).

Aparte del intercambio cultural, el CUNA, con ayuda tanto de varias tribus Kumeyaay como de las instituciones gubernamentales y las universidades de ambos lados de la frontera, puso en marcha varios proyectos para prestar asistencia a las comunidades kumiai en materia de salud, medio ambiente y cruce fronterizo (para más detalles, véase Von Barsewisch, 2006). Asimismo, organizan donaciones transnacionales para las ocasiones especiales, como la Navidad y Los Reyes Magos, cuando los miembros de diferentes tribus Kumeyaay traen despensas y/o regalos a las comunidades nativas de Baja California.

Un logro muy representativo entre los proyectos transnacionales es la consecución de la visa láser para los miembros kumiai del lado mexicano mediante el Kumeyaay Border Task Force Program. Este programa empezó a principios de 1 os noventa por la iniciativa de algunos Kumeyaay e involucró al CUNA y a las tribus Kumeyaay. ${ }^{27}$

La obtención de la visa llegó a ser una necesidad a medida que el control fronterizo aumentaba gradualmente. Hasta la década de los ochenta los kumiai mexicanos cruzaban la frontera con la identificación emitida por el Instituto Nacional Indigenista de México (INI), sin embargo, a partir de su endurecimiento, sobre todo de la implementación de la Operation Gatekeeper (1994), ya no había más remedio que conseguir la visa para asegurar el cruce fronterizo (Von Barsewisch, 2006; Luna-Firebaugh, 2002). ${ }^{28}$ Para los kumiai, una de las mayores barreras fue arreglar los documentos requeridos, a saber, el pasaporte y la visa, y solventar los gastos, no solo de estos documentos, sino también del traslado. Además, algunas personas mayores no podían tramitar el pasaporte mexicano ya que tenían el acta de nacimiento extemporánea (Morris, 2015). Por tanto, lo que hizo el programa fue crear el sistema de traslado y cubrir el gasto de la comunidad al consulado mexicano en San Diego para realizar el trámite de pasaporte, donde se aceptaba el acta extemporánea, y posteriormente de la comunidad al CBP, en la puerta de Tecate para tramitar la visa. Las comunidades kumiai en el lado mexicano, a su vez, emprendieron la tarea de elaborar el censo comunitario con el fin de entregar la lista de miembros ante el CBP (Morris, 2015), de tal

\footnotetext{
${ }^{25}$ Se estima que en México existen 50 hablantes de kumiai, mientras en Estados Unidos el uso de la lengua vernácula está casi obsoleto (Field y Meza, 2012).

${ }^{26}$ La fiesta nativa es un festival organizado por el CUNA que se celebra cada año en Ensenada, Baja California, en donde participan los yumanos de Baja California, así como algunos miembros de las tribus de California. Se realizan varias actividades culturales (concursos, danzas, etc.), venta de artesanías y de comida tradicional.

${ }^{27}$ Von Barsewisch indica que no todas las tribus estaban de acuerdo en apoyar este programa (2006: 103). Si bien había una movilidad a lo largo del tiempo en la región transfronteriza, los lazos sociales y de parentesco son más fuertes entre los que habitan alrededor de la línea fronteriza.

${ }^{28}$ Además, ambas autoras afirman que también se presentaba un mal uso de la tarjeta del INI: las personas no indígenas empezaron a utilizar esta tarjeta para cruzar la frontera, con lo que los agentes de la frontera dejaron de aceptar esta identificación para el cruce fronterizo (Von Barsewisch, 2006; Luna-Firebaugh, 2002).
}

EntreDiversidades. Revista de Ciencias Sociales y Humanidades, Vol. 9, Núm. 1 (18), enero-junio 2022. Páginas: 148-175 ISSN-e: 2007-7610. https://doi.org/10.31644/ED.V9.N1.2022.A06 
forma que los agentes de esta institución pudieran identificarlos como kumiai y les autorizaran la visa. Aunque el costo de pasaporte y visa corría a cargo de cada individuo, la mayoría de los miembros consiguieron la visa a través de este programa y cruzaron la frontera para participar en eventos culturales o para vender artesanías (Von Barsewisch, 2006; Morris, 2015). Además, es importante enfatizar que este programa les condujo a pensar en fronteras comunitarias dentro de México y que los kumiai construyeron —ya sea temporalmente o no- la frontera de pertenencia comunitaria y étnica acorde con el consenso de cada comunidad.

Sin embargo, debido a las dificultades en la coordinación entre diferentes organizaciones e irregularidades en el cruce fronterizo, el programa dejó de operar, y, por consecuencia, después de cumplir la vigencia de visa pocas personas pudieron renovarla por falta de recursos. Aunado a la crisis económica de 2008 y las problemáticas arriba mencionadas, optaron por utilizar solo el permiso cultural en la puerta de Tecate, cuyos agentes ya tienen experiencia de haber trabajado con los kumiai/Kumeyaay. Actualmente, los miembros mexicanos cruzan la frontera con el permiso cultural, es decir, con el pasaporte mexicano y carta de invitación emitida por las tribus estadounidenses, en las cuales especifican motivos y fechas del evento cultural a los que invitan (Morris, 2015). Si bien los kumiai en el lado mexicano siguen cruzando la frontera de esta manera, lo hacen con mucha limitación y poca libertad; solo les permiten el viaje en grupo para eventos culturales - a pesar de que lo que implica "la cultura" es diferente entre los kumiai/Kumeyaay y los agentes del CBP (directora de Sycuan Cultural Department, entrevista en diciembre, 2018) —, en general con poco tiempo de estancia. Lo peor de este sistema, igual que en el caso de los yaquis, es que los kumiai de México no pueden cruzar la frontera sin invitación formal y previa de las tribus estadounidenses (Morris, 2015). Esta situación empeoró bajo el gobierno de Trump, pues imperaba la incertidumbre en la frontera, la gente evitó solicitar el permiso y disminuyó considerablemente el flujo de personas y cosas. En este sentido, podemos decir que el permiso cultural, lejos de ser una respuesta favorable y humanitaria del Estado a las demandas de los pueblos indígenas transfronterizos, es una política eficaz para identificar a la población y controlar el flujo dando la apariencia de política de reconocimiento, ya que los propios indígenas asumen el riesgo como nación "soberana".

\section{A manera de conclusión}

En este trabajo menciono algunos cambios que ocurrieron en México y Estados Unidos durante las décadas anteriores y sugiero que dichos cambios crearon base para la transnacionalización de los pueblos indígenas en la frontera, dando como resultado las resistencias y articulaciones transnacionales en diferentes ámbitos. Si bien las políticas del multiculturalismo neoliberal, junto con los movimientos indígenas a escala global, abrieron el camino para la transnacionalización de los pueblos indígenas en la frontera, debido a la relación asimétrica entre el Estado y las naciones tribales les es imposible salir de los marcos institucionales nacionales, y terminan, de mala gana, aceptando las categorías nación-centristas impuestas por la frontera hegemónica.

En la era de multiculturalismo neoliberal la articulación entre las diversas fuerzas más allá de las fronteras es fundamental para hacer más visible la resistencia y hacer escuchar sus demandas.

EntreDiversidades. Revista de Ciencias Sociales y Humanidades, Vol. 9, Núm. 1 (18), enero-junio 2022. Páginas: 148-175 ISSN-e: 2007-7610. https://doi.org/10.31644/ED.V9.N1.2022.A06 
En este sentido, las movilizaciones y los esfuerzos para la reorganización étnica a lo largo de las últimas tres décadas trajeron consecuencias significativas. El surgimiento de identidades culturales y políticas rebasa la línea divisoria y crea las prácticas transnacionales para desafiar a las fuerzas del poder. El intercambio transnacional no solo repercute en la esfera cultural, sino también en la vida política, pues los pueblos indígenas en la frontera ahora comparten las estrategias y tácticas de luchas formales e informales para que los Estados reconozcan y protejan sus derechos. Sin embargo, aún queda el gran reto de la cooperación en el aspecto económico, pues las diferencias legales e institucionales entre ambos países, así como la condición política particular de los Native American, dificultan la transferencia de recursos fuera del territorio estadounidense para arrancar un proyecto económico o social; el don transnacional sí les ayuda, pero no puede transformar la realidad social ni mitigar la pobreza.

Después de pasar el auge de la transnacionalidad en los noventa, estos pueblos experimentan más las fronteras entre sí mismos. Ni que decir tiene la militarización de la frontera — que también es el resultado de la política neoliberal—. Las políticas del multiculturalismo neoliberal, además de incitar a la exclusión y la desposesión de los indígenas mexicanos y algunos Native American, sellan y refuerzan las fronteras, entre los indígenas y los mestizos, entre Native American reconocidos y los no reconocidos, entre los grupos exitosos y los empobrecidos, entre los miembros mexicanos y los estadounidenses. La comunicación y la coordinación entre los agentes de ambos lados de la frontera ha sido difícil por varias razones, y también esto se debe a la falta de una organización o asociación transnacional donde con participación de los miembros de ambos lados de la frontera se discuta y se trabaje en conjunto para planear proyectos que tengan realmente un impacto social, ya sea para la revitalización cultural o para la erradicación de la pobreza.

Finalmente, argumenté que aún en el mundo globalizado la frontera baja cada vez más su permeabilidad a los indígenas fronterizos del lado mexicano. A pesar de los esfuerzos constantes de facilitar el cruce fronterizo, los miembros del lado mexicano tienen derechos mínimos en el territorio estadounidense y entran a condición de que las tribus emparentadas sean responsables de estos mientras permanecen ahí. Aquí, esta excepcionalidad debe analizarse desde la perspectiva de la gubernamentalidad del Estado y compararse con la otra frontera, la de Canadá y Estados Unidos, ya que los indígenas canadienses, independientemente de que sean de las tribus transfronterizas o no, tienen derecho del libre cruce fronterizo así como de vivir y trabajar en el territorio estadounidense (Luna-Firebaugh, 2002). ${ }^{29}$

\section{Bibliografía citada}

Amoore, Louise (2006). "Biometric Borders: Governing Mobilities in the War on Terror" Political Geography Quaterly [en línea], 25 (3), pp. 336-351. doi: https://doi.org/10.1016/j. polgeo.2006.02.001 (Consultado el 10 de febrero de 2017).

\footnotetext{
${ }^{29}$ Entre estos pueblos o naciones en la frontera Estados Unidos-Canadá, el caso de los Mohawk es interesante (véase Simpson, 2014). Luna-Firebaugh (2002) también señala casos de algunos grupos fronterizos, como el de Blackfeet Nation.
}

EntreDiversidades. Revista de Ciencias Sociales y Humanidades, Vol. 9, Núm. 1 (18), enero-junio 2022. Páginas: 148-175 ISSN-e: 2007-7610. https://doi.org/10.31644/ED.V9.N1.2022.A06 
Banegas, Ethan L. (2017). The Socioeconomic Impact of Indian Gaming on Kumeyaay Nations: A Case Study of Barona, Viejas, and Sycuan, 1982 - 2016. Tesis para obtener el grado de Masters of Arts in History, University of San Diego. Disponible en: https://doi. org/10.22371/02.2017.021 (Consultado el 27 de marzo de 2021).

Bartolomé, Miguel Alberto (2008). "Fronteras estatales y fronteras étnicas en América Latina. Notas sobre el espacio, la temporalidad y el pensamiento de la diferencia”, en Velasco Ortiz, Laura (coord.). Migración, fronteras e identidades étnicas transnacionales. México: El Colegio de la Frontera Norte, Miguel Ángel Porrúa, pp. 35-78.

Besserer, Federico (1999). "Estudios trasnacionales y ciudadanía transnacional", en Mummert, Gail (ed.). Fronteras Fragmentadas. México: El Colegio de Michoacán, Centro de Investigación y Desarrollo del Estado de Michoacán, pp. 215-238.

Besserer, Federico y Nieto, Raúl (2015). "La ciudad transnacional comparada: derroteros conceptuales", en Besserer, Federico y Nieto, Raúl (eds.). La ciudad transnacional comparada: modos de vida, gubernamentalidad y desposesión. Ciudad de México, México: Universidad Autónoma Metropolitana-Unidad Iztapalapa, Juan Pablos Editor, pp. 15-50.

Biolsi, Thomas (2004). "Political and Legal Status ("Lower 48" States)", en Biolsi, Thomas (ed.). A Companion to the Anthropology of American Indians. Malden, Massachusetts, United States of America, Oxford, United Kingdom, Victoria, Australia: Blackwell Publishing, pp. 231-247.

Biolsi, Thomas (2005). "Imagined Geographies: Sovereignty, Indigenous Space, and American Indian Struggle”. American Ethnologist [en línea], 32 (2), pp. 239-259. doi: https://doi. org/10.1525/ae.2005.32.2.239 (Consultado el 23 de noviembre de 2016).

Briones, Claudia, et al. (2007). "Escenas del multiculturalismo neoliberal. Una proyección desde el Sur", en Grimson, Alejandro (comp.). Cultura y Neoliberalismo. Buenos Aires, Argentina: Consejo Latinoamericano de Ciencias Sociales, pp. 265-299. Disponible en: http://bibliotecavirtual.clacso.org.ar/ar/libros/grupos/grim cult/Briones-Canuquenoetc.pdf (Consultado el 6 de agosto de 2021).

Cañas Cuevas, Sandra (2016). "Pueblo trágico: gubernamentalidad neoliberal y multicultural en el sureste mexicano". Revista Pueblos y fronteras digital [en línea], 11 (21), pp. 3-30. doi: https://doi.org/10.22201/cimsur.18704115e.2016.21.6 (Consultado el 5 de marzo de 2021).

Castile, George Pierre (2002). "Yaquis, Edward H. Spicer, and Federal Indian Policy: From Immigrants to Native Americans". Journal of the Southwest, 44 (4), pp. 383-435.

Clifford, James (2013). Returns. Being Indigenous in the Twenty-First Century. Cambridge, Massachusetts, United States of America, London, United Kingdom: Harvard University Press.

Comaroff, John L. y Comaroff, Jean (2009). Ethnicity Inc. Chicago, United States of America, London, United Kingdom: University of Chicago Press.

Donnan, Hastings y Wilson, Thomas M. (1999). Borders. Frontiers of Identity, Nation and State. Oxford, United Kingdom, New York, United States of America: Berg.

EntreDiversidades. Revista de Ciencias Sociales y Humanidades, Vol. 9, Núm. 1 (18), enero-junio 2022. Páginas: 148-175 ISSN-e: 2007-7610. https://doi.org/10.31644/ED.V9.N1.2022.A06 
Field, Margaret y Meza Cuero, Jon (2012). "Kumeyaay Oral Tradition, Cultural Identity, and Language Revitalization”. Oral Tradition [en línea], 27 (2), pp. 319-332. Disponible en: https://journal.oraltradition.org/wp-content/uploads/files/articles/27ii/04 27.2.pdf (Consultado el 5 de marzo de 2021).

Fukuma, Mao (2011). Dos comunidades yaquis fronterizas: don, intercambio e identidad. Tesina para obtener el grado de Maestría en Ciencias Antropológicas, División de Ciencias Sociales y Humanidades, Universidad Autónoma Metropolitana, Unidad Iztapalapa, México. También disponible en: http://tesiuami.izt.uam.mx/uam/aspuam/presentatesis. php?recno=15635\&docs=UAMI15635.pdf

Fukuma, Mao (2018). Hacia la trans-nación yaqui: intercambio, fronteras e identidades. Tesis para obtener el grado de Doctorado en Ciencias Antropológicas, División de Ciencias Sociales y Humanidades, Universidad Autónoma Metropolitana, Unidad Iztapalapa, México. También disponible en: http://tesiuami.izt.uam.mx/uam/aspuam/presentatesis. php?recno=22414\&docs=UAMI22414.pdf

Garduño Ruiz, Everardo (2004). "Cuatro ciclos de resistencia indígena en la frontera México-Estados Unidos”. ERLACS. Revista Europea de Estudios Latinoamericanos y del Caribe [en línea], Núm. 77, pp. 41-60. doi: https://doi.org/10.18352/erlacs.9677 (Consultado el 10 de octubre de 2019).

Garduño Ruiz, Everardo (2014a). "El riesgo y el rescate. La tradición y la innovación como factores de identidad”. Revista Digital Universitaria [en línea], 15 (2), pp. 2-20. Disponible en: http://www.revista.unam.mx/vol.15/num2/art08/index.html (Consultado el 5 de marzo de 2021).

Garduño Ruiz, Everardo (2014b). De lugares con historia e historia sin lugar. Geografía simbólica del pueblo kumiai. San Bernardino, California, Estados Unidos: Abismos Editorial, School of Transborder Studies, Arizona State University, Instituto de Investigaciones Culturales-Museo, Universidad Autónoma de Baja California.

Garduño Ruiz, Everardo (2016). Los kumiai. Mexicali, Baja California, México: Universidad Autónoma de Baja California, Instituto de Investigaciones Culturales-Museo.

Glick Schiller, Nina, Linda Basch y Cristina Blanc-Szanton (1992). "Transnationalism: A New Analytic Framework for Understanding Migration”. Towards a Transnational Perspective on Migration; Race, Class, Ethnicity and Nationalism Reconsidered, Annals of the New York Academy of Science [en línea], 645 (1), pp. 1-24. doi: https://doi. org/10.1111/j.1749-6632.1992.tb33484.x (Consultado el 16 de abril de 2021).

Guidotti-Hernández, Nicole. M. (2011). Unspeakable Violence. Remapping U.S. and Mexican National Imaginaries. Durham, London, United Kingdom: Duke University Press.

Hale, Charles (2005a). "El protagonismo indígena: las políticas estatales y el nuevo racismo en la época del 'indio permitido"'. En: Paz y democracia en Guatemala: desafios pendientes. Memoria del Congreso Internacional de MINUGUA. "Construyendo la paz: Guatemala desde un enfoque comparado”. Ciudad de Guatemala, Guatemala: Fundación Propaz, pp. 51-66.

EntreDiversidades. Revista de Ciencias Sociales y Humanidades, Vol. 9, Núm. 1 (18), enero-junio 2022. Páginas: 148-175 ISSN-e: 2007-7610. https://doi.org/10.31644/ED.V9.N1.2022.A06 
Hale, Charles (2005b). "Neoliberal Multiculturalism: The Remarking of Cultural Rights and Racial Dominance in Central America”. PoLAR Political and Legal Anthropology Review [en línea], 28 (1), pp. 10-28. Disponible en: http://www.jstor.org/stable/24497680 (Consultado el 2 de junio de 2020).

Hale, Charles (2016). "Rethinking Indigenous Politics in the Era of the 'Indio Permitido"'. NACLA Report on the Americas [en línea], 38 (2), pp. 16-21. doi: https://doi.org/10.108 0/10714839.2004.11724509 (Consultado el 10 de abril de 2020).

Hanson, Randel D. (2004). "Contemporary Globalization and Tribal Sovereignty", en Biolsi, Thomas (ed.). A Companion to the Anthropology of American Indians. Malden, Massachusetts, United States of America, Oxford, United Kingdom, Victoria, Australia: Blackwell Publishing, pp. 284-303.

Harvey, David (2007). Breve historia del neoliberalismo. Madrid, España: Ediciones Akal.

Hays, Rachel (1996). "Cross-border Indigenous Nations: A History". Race, Poverty \& the Environment [en línea], Vol. 6/7, pp. 40-42. Disponible en: http://www.jstor.org/ stable/41495630 (Consultado el 11 de noviembre de 2016).

Herrera Acevedo, Ileana Gabriela (2016). Quince años después: desarrollo local por la actividad de turismo alternativo en zonas indígenas (2000-2016). San José de la Zorra y San Antonio Necua, Baja California. Tesis para obtener el grado de Maestría en Desarrollo Regional, El Colegio de la Frontera Norte, México. Disponible en: https://colef.repositorioinstitucional. mx/jspui/handle/1014/271 (Consultado el 3 de marzo de 2021).

Hu-DeHart, Evelyn (1984). Yaqui Resistance and Survival: The Struggle for Land and Autonomy 1821-1910. Madison, Wisconsin, United States of America: University of Wisconsin Press.

Jones, J. Harry (2017). "Gambling gone bust, tribe turns to marijuana farming”. Los Angeles Times [en línea], 3 de mayo. Disponible en: https:/www.latimes.com/local/lanow/la-meindian-pot-farm-20170503-story.html (Consultado el 28 de septiembre de 2021).

Jung, Courtney (2003). "The Politics of Indigenous Identity: Neo-liberalism, Cultural Rights, and the Mexican Zapatistas". Social Research: An International Quarterly [en línea], 70 (2), pp. 433-462. Disponible en: https://muse.jhu.edu/article/558573/pdf (Consultado el 10 de marzo de 2021).

Kearney, Michael (2006). "El poder clasificador y filtrador de las fronteras”, en Besserer, Federico y Kearney, Michael (eds.). San Juan Mixtepec, una comunidad transnacional ante el poder clasificador y filtrador de las fronteras. México, D.F., México: Casa Juan Pablos, Universidad Autónoma Metropolitana-Unidad Iztapalapa, pp. 31-71.

Kearney, Michael y Nagengast, Carole (1989). Anthropological Perspectives on Transnational Communities in Rural California, Working Paper No. 3. Working Group on Farm Labor and Rural Poverty. Davis, California, United States of America: California Institute for Rural Studies.

Lerma Rodríguez, Enriqueta (2015). "En busca de la autonomía entre los yaquis. Múltiples proyectos de desarrollo y una sola "gran verdad»". Revista Pueblos y fronteras digital [en línea], 10 (19), pp. 285-307. doi: https://doi.org/10.22201/ cimsur.18704115e.2015.19.54 (Consultado el 4 de febrero de 2021).

EntreDiversidades. Revista de Ciencias Sociales y Humanidades, Vol. 9, Núm. 1 (18), enero-junio 2022. Páginas: 148-175 ISSN-e: 2007-7610. https://doi.org/10.31644/ED.V9.N1.2022.A06 
Leza, Christina (2009). Divided Nations: Policy, Activism and Indigenous Identity on the U.S. Mexico Border. Tesis para obtener el grado de Doctorado en Filosofía, Department of Anthropology, University of Arizona, U.S. Disponible en: https://repository.arizona.edu/bitstream/ handle/10150/193815/azu etd 10782 sip 1 m.pdf? sequence $=1$ \&isAllowed $=y$ (Consultado el 10 de enero de 2016).

Levitt, Peggy y Glick Schiller, Nina (2004). "Perspectivas internacionales sobre migración: conceptuar la simultaneidad". Migración y Desarrollo [en línea], 2 (3), pp. 60-91. doi: https://doi.org/10.35533/myd.0203.pl.ngs (Consultado el 23 de julio de 2015).

Luna-Firebaugh, Eileen M. (2002). "The Border Crossed Us: Border Crossing Issues of the Indigenous Peoples of the Americas". Wicazo Sa Review [en línea], 17 (1), pp. 159-181. doi: https://doi.org/10.1353/wic.2002.0006 (Consultado el 21 de abril de 2017).

Magaña Mancillas, Mario Alberto (2010). Indios, soldados y rancheros. Poblamiento, memoria e identidades en el área central de las Californias (1769-1870). Baja California Sur, México: Gobierno del Estado de Baja California Sur, Secretaría de Cultura, Instituto Sudcaliforniano de Cultura y Archivo Histórico Pablo L. Martínez.

Mager Hois, Elisabeth A. (2010). Casinos y poder. El caso de Kickapoo Lucky Eagle Casino. México, D.F., México: Universidad Nacional Autónoma de México, Centro de Investigaciones sobre América del Norte, Instituto de Investigaciones Antropológicas, Facultad de Estudios Superiores Acatlán.

Miller, Mark Edwin (2004). Forgotten Tribes: Unrecognized Indians and Federal Acknowledgment Process. Lincoln, Nebraska, United States of America: University of Nebraska Press.

Morris, Olea Elizabeth B. (2015). Kumeyaay Across Borders: An Evaluation of Formal and Informal Approaches to Tribal Transportation Issues. Tesis para obtener el grado de Mestría en Antropología, San Diego State University, U.S. Disponible en: https://digitallibrary.sdsu. edu/islandora/object/sdsu\%3A2088 (Consultado el 5 de marzo de 2021).

Olmos Aguilera, Miguel (2007). “Antropología de la frontera: ‘tiempo de híbridos?”, en Olmos Aguilera, Miguel (cord.). Antropología de las fronteras. Alteridad, historia e identidad más allá de la línea. México, D.F., México: El Colegio de la Frontera Norte, Miguel Ángel Porrúa, pp. 19-38.

Ong, Aihwa (2006). Neoliberalism as Exception: Mutations in Citizenship and Sovereignty. Durham, United Kingdom: Duke University Press.

Ota, Yoshinobu (1998). Transposition no shisou. Japan: Sekaishisousha.

Padilla Ramos, Raquel (1995). Yucatán, fin del sueño yaqui: el tráfico de los yaquis y el otro triunvirato. Sonora, México: Gobierno del Estado de Sonora, Secretaría de Educación y Cultura, Instituto Sonorense de Cultura.

Padilla Ramos, Raquel (2009). Los partes fragmentados narrativas de la guerra y la deportación yaquis. Tesis para obtener el grado de Doctorado en Filosofía, Universität Hamburg, Germany. Disponible en: https://ediss.sub.uni-hamburg.de/bitstream/ediss/2995/1/ Raquel Padilla dissertation.pdf (Consultado el 8 de marzo de 2021).

EntreDiversidades. Revista de Ciencias Sociales y Humanidades, Vol. 9, Núm. 1 (18), enero-junio 2022. Páginas: 148-175 ISSN-e: 2007-7610. https://doi.org/10.31644/ED.V9.N1.2022.A06 
Pallitto, Robert y Heyman, Josiah (2008). “Theorizing Cross-Border Mobility: Surveillance, Security and Identity". Surveillance \& Society [en línea], 5 (3), pp. 315-333. doi: https://doi.org/10.24908/ss.v5i3.3426 (Consultado el 10 de junio de 2016).

Reygadas, Luis (2007). "La desigualdad después del (multi)culturalismo", en Giglia, Angela, Carlos Garma y Ana Paula de Teresa (comp.). Adónde va la antropología. México, D.F., México: Universidad Autónoma Metropolitana-Unidad Iztapalapa, Juan Pablos Editor, pp. 341-364.

Rivera Cusicanqui, Silvia (2016). "Etnicidad estratégica, nación y (neo)colonialismo en América Latina". Alternativa. Revista de Estudios Rurales, Núm. 5, pp. 65-87.

Saldívar, Emiko (2003). "Indigenismo Legal: la política indigenista de los noventas". Revista Mexicana de Ciencias Politicas y Sociales [en línea], 46 (188-9), pp. 311-337. doi: http://dx.doi.org/10.22201/fcpys.2448492xe.2003.188-9.42425 (Consultado el 8 de marzo de 2016).

Santiago Guerrero, Bibiana L. (2006). Aqui no pasa nada. La gente al pie del Cuchumá: memoria histórica de Tecate. México: Instituto de Investigaciones Históricas, Universidad Autónoma de Baja California, La fundación Rancho a la Puerta, A.C.

Simpson, Audra (2014). Mohawk Interruptus. Political Life Across the Borders of Settler States. Durham, United Kingdom: Duke University Press.

Schulze, Jeffrey M. (2008). Trans-Nations: Indians, Imagined Communities and Border Realities in the Twentieth Century. Tesis para obtener el grado de Doctorado en Filosofía, Graduate Faculty of Dedman College, Southern Methodist University, U.S.

Shipek, Florence Connolly (1991). Delfina Cuero. California, United States of America: Ballena Press.

Spicer, Edward H. (1994). Los Yaquis: historia de una cultura. México, D.F., México: Universidad Nacional Autónoma de México.

Von Barsewisch, Alexandra (2006). “Tipai Uam’: el recorrido indio. Kumeyaay courses astride la línea”. Culturales [en línea], 2 (3), pp. 52-110. Disponible en: http://culturales.uabc.mx/ index.php/Culturales/article/view/42 (Consultado el 24 de mayo de 2017).

Valladares, Laura (2008). "La política de la multiculturalidad en México y sus impactos en la movilización indígena: avances y desafíos en el nuevo milenio”, en García, Fernando (coord.). Identidades, etnicidad y racismo en América Latina. Quito, Ecuador: Facultad Latinoamericana de Ciencias Sociales-Sede Ecuador, pp. 289-308. Disponible en: https:// biblio.flacsoandes.edu.ec/libros/digital/41402.pdf (Consultado el 10 de abril de 2021).

Weaver, Thomas, et al. (eds.) (2012). Neoliberalism and Commodity Production in Mexico. Boulder, Colorado, United States of America: University Press of Colorado.

Yuman Language Family Summit (s.f.). Goals and Objectives of The Annual Yuman Language Family Summit Voted on by Steering Committee Members 2002 [en línea]. Disponible en: http://www.yumanlanguagefamilysummit.com/ (Consultado el 20 de mayo de 2021).

EntreDiversidades. Revista de Ciencias Sociales y Humanidades, Vol. 9, Núm. 1 (18), enero-junio 2022. Páginas: 148-175 ISSN-e: 2007-7610. https://doi.org/10.31644/ED.V9.N1.2022.A06 